\title{
Pengembangan dan Pemanfaatan Desain Kemasan sebagai Media Promosi pada UKM Heavenine
}

\author{
I Gusti Ayu Desi Saryanti ${ }^{1 *}$, Erlinda Mandasari ${ }^{2}$, I Gusti Ayu Putri Indah Sidhiantari ${ }^{3}$ \\ ${ }^{1,2,3}$ Prodi Sistem Informasi, Institut Teknologi dan Bisnis STIKOM Bali \\ 1desi@stikom.ac.id, 2lindamandasari@gmail.com, 3indahsidhiantari@ gmail.com
}

\begin{abstract}
Heavenine is one of the UKM which is engaged in the craft of making Balinese souvenirs. The products produced at this UKM are various kinds of Balinese souvenirs such as clothes, glass bags, umbrellas that have a characteristic Balinese image. Promotion is the one way to introduce products owned by a company or UKM. At this time, the promotion method carried out at UKM Heavenine is still fairly simple, promotions are carried out only around the region or by participating in exhibitions in one place so that there is a lack of breadth of the promotion network they have make the income is unstable. For this reason, the indicators of achievement in community service will be carried out by developing and utilizing packaging design as a promotional medium with the purpose of further expanding the trade network and increasing income for Heavenine UKM
\end{abstract}

Keywords : Packaging Design, UKM, Heavenine

Abstrak

Heavenine merupakan salah satu UKM yang bergerak dibidang kerajinan pembuatan souvenir khas Bali. Produk yang dihasilkan pada UKM ini yaitu berbagai macam souvenir khas bali seperti baju, tas gelas, payung yang memiliki ciri khas gambar Bali. Promosi merupakan salah satu cara untuk mengenalkan produk yang dimiliki oleh suatu perusahaan atau UKM. Pada saat ini metode promosi yang dilakukan pada UKM Heavenine masih terbilang sangat sederhana, promosi dilakukan hanya di seputaran daerah saja atau memgikuti pameran yang ada di suatu tempat sehingga kurang luasnya jaringan promosi yang dimiliki yang mengakibatkan penghasilan tidak stabil. Untuk itu indikator pencapaian pada pengabdian masyarakat ini akan dilakukan pengembangan dan pemanfaatan Desain kemasan sebagai media promosi dengan tujuan untuk lebih meluaskan jaringan perdagangan dan penghasilan lebih meningkat pada UKM Heavenine.

Kata Kunci: Desain Kemasan, UKM, Heavenine

*Penulis Korespondensi : I Gusti Ayu Desi Saryanti

\section{PENDAHULUAN}

Souvenir atau cinderamata merupakan barang-barang kerajinan tangan yang merupakan hasil kreativitas para pengerajin. Suatu benda yang identik dengan suatu daerah tertentu yang memiliki ciri yang khas sehingga memiliki daya tarik oleh pembeli sebagai cindramata atau oleh untuk kerabat atau teman. Banyak jenis cindramata yang ada yaitu baju, mugs, tas dan masih banyak lagi yang lainnya. Desain kemasan juga tidah bisa dipisahkan dari sebuah bisnis. Agar bisnis dapat berjalan lancer segala aspek perlu diperhatikan agar mendapatkan daya tarik dan kenyamanan bagi konsumen.

Desain kemasan produk merupakan salah satu faktor penting yang dapat menguatkan branding bisnis dalam persaingan yang semakin ketat. Desain kemasan yang menarik dan berkualitas menjadi pembeda antara brand sendiri dengan kompetitor. Melalui desain kemasan produk, kita dapat menyampaikan informasi mengenai identitas bisnis UKM tersebut seperti logo, kualitas produk, dan sebagainya. Hal seperti ini tentu bisa menarik perhatian pelanggan terhadap 
produk yang kita miliki. Apalagi di Bali sendiri penggunakan plastik sudah dilarang sesuai dengan peraturan pemerintah.

Mitra pada UKM ini adalah Heavenine dimana usaha ini bergerak pada bidang kerajinan atau pembuatan souvenir yang memiliki ciri khas bali seperti tas, baju, mugs dal lainnya. UKM Heavenine beralamat di jalan di Desa Akah, Klungkung. Lokasi tersebut dapat ditempuh dalam waktu kurang lebih 55 menit dari lokasi pengusul. Jarak yang ditempuh pengusul ke Desa Akah dengan jarak $35.1 \mathrm{~km}$. UMKM perlu dikembangkan karena dapat menjadi usaha yang besar sehingga dapat meningkatkan roda perekonomian. Cara peningkatan terhadap UMKM antara lain dengan melakukan pemasaran produknya melalui teknologi informasi [1][2]. promosi yang dilakukan saat ini masih sangat umum hanya menawarkan kepada setiap pelanggan dan beberapa kali melakukan pameran pada even yang sedang berlangsung seperti Pesta Kesenian Bali dan Denpasar Festival. Serta dari segi pengemasannya sebelumnya menggunakan tas plastik namun semenjak plastik dilarang penggunaannya penjual hanya memberikan barang begitu saja kepada pembeli. Dari hal tersebut untuk membantu mitra dalam usahanya, pengusul akan memberikan pengenalan mengenai pemanfaatan Desain Kemasan menggunakan paper bag yang nantinya akan berisikan identitas dari UKM seperti logo, alamat kontak yang dapat dihubungi.

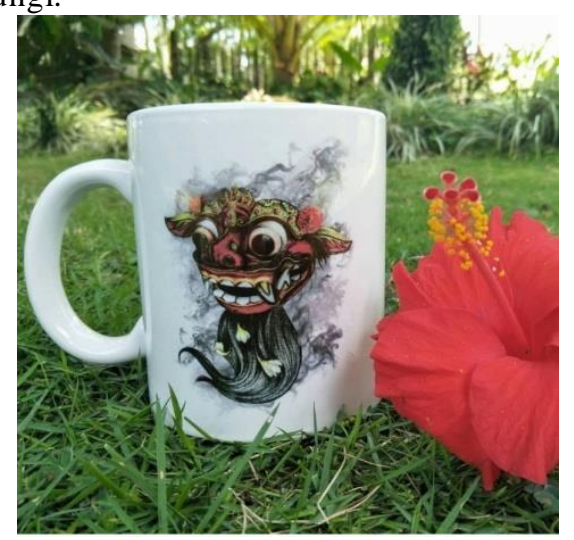

Gambar 1. Produk dari UKM

Berdasarkan hasil analisa terhadap situasi existing maka diketahui permasalahan prioritas mitra adalah sebagai berikut:

1. Desain Kemasan sangat penting dilakukan agar menambah daya Tarik pembeli serta secara tidak langsung mempromosikan produk yang dimikili dengan mecantumkan logo, alamat, kontak pada paperbag.
2. Memperkenalkan usaha souvenir pada UKM Heavenine kepada masyarakat luas.

3. Keterbatasan pengetahuan pemilik UKM dalam pemanfaatan teknologi informasi kususnya Pembuatan Desain Kemasan sebagaimedia promosi.

4. Tidak pernah adanya pelatihan atau sosialisasi untuk mengajarkan mereka mengenai Penggunaan Desain Kemasan dalam mengembangkan usahanya.

\section{METODE}

Metode yang digunakan pada kegiatan ini terdiri dari pengumpulan dan analisis data. Data yang didapat dari proses tersebut, digunakan sebagai bahan untuk merancang label kemasan pada MKM Heavenine. Perancangan label kemasan dilakukan dengan menggunakan teori desain kemasan.[3]

Prosedur kerja dari kegiatan ini terdapat beberapa tahap yakni kegiatan ini dimulai dari sosialisasi kegiatan, pngembangan dan penerapan penggunaan Desain Kemasan, dan evaluasi kegiatan.

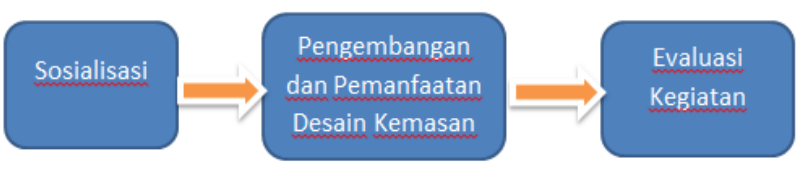

Gambar 2. Alur Pengabdian

1. Sosialisasi dilaksanakan dengan menghadirkan mitra dalam pertemuan. Pada pertemuan tersebut akan disampaikan informasi-informasi mengenai latar belakang, target, sasaran dan tujuan kegiatan. Disamping menyampaikan maksud dan tujuan, juga dilakukan pencatatan data teknis lebih lanjut serta pencatatan visualisasi dalam bentuk video dan foto. Dokumentasi ini digunakan dalam desiminasi atau pemasyarakatan hasil pelaks anaan program.

2. Penerapan Pemanfaatan Desain kemasan, untuk dapat mengakses internet akan digunakan alat bantu laptop dan modem sehingga penerapan akan dapat dilaksanakan. dengan akses yang baik, maka proses akan menjadi lebih efektif. Setelah memperoleh akses internet, dengan bantuan fasilitas penyedia koneksi internet, pengguna atau user juga dipandu untuk dapat membuat email, dan mendaftarkan diri sekaligus memanfaatkan situs penjualan online yang tersedia.Tahap berikutnya dengan mengar ahkan cara menggunakan Internet.[6] 
3. Evaluasi kegiatan dilakukan setelah penggunaan Desain Kemasan dilakukan, evaluasi dilakukan dengan melihat hasil dari pembelajaran mereka dan tingkat penggunaan desain kemasan yang akan di cantumkan pada paper bag.

\section{ANALISIS DATA}

a. Metode SWOTAnalisis data dengan menggunakan metode SWOT(Strengths, Weaknesses, Opportunities, Threats) dilakukan untuk menentukan rancangan label dan banneryang tepat sesuai dengan keadaan UMKM mitra. Analisis SWOT. Pada umumnya digunakan untuk menentukan strategi bisnis berdasarkan strengths, weaknesses, opportunities, dan threats terhadap sebuah perusahaan .[4]

b. Metode VIEWMetode VIEW (Visibility, Information, Emotional Appeal, Workability) digunakan sebagai acuanuntuk masalah teknis dalam merancanglabel dan banner. Label dan banneryang dirancang harus memiliki tampilan yang menarik konsumen (Visibility), informasi tentang produk (Information), menarik konsumen secara emosional dengan memberikan perasaan/emosi tertentu (Emotional Appeal), dan fungsionalitas dari label dan banner(Workability).[5]

\section{HASIL DAN PEMBAHASAN}

Pengabdian Masyarakat bertujuan untuk membantu UKM dalam memajukan usaha yang dibangun. Dalam hal ini pengusul membantu mitra dalam bidang promosi yaitu menggunakan media Teknologi Informasi kususnya dalam bidang Desain. Pada pembahasan ini akan menjelaskan bagaimana dari tahap awal dilakukan yaitu sosialisasi kepada mitra, penerapan dan pengembangan menggunakan Desain Kemasan dimana UKM akan dibuatkan Desain sesuai keinginan mitra dimana akan berisikan logo UKM, alamat dan kontak pemilik UKM.

\section{Lokasi Pengabdian}

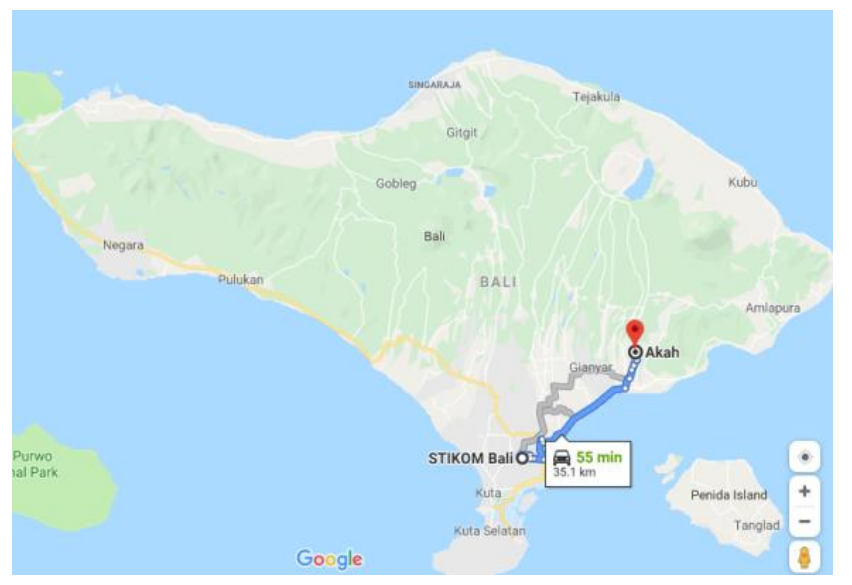

Gambar 3. Lokasi Pengabdian

Pada gambar dibawah ini akan menggambarkan jarak lokasi pengusul dengan lokasi pengabdian masyarakat. Lokasi akan di tempuh kurang lebih selama 55menit dari lokasi pengusul. Jarak yang di tempuh pengusul dari lokasi pengusulk ke lokasi pengabdian masyarakat menempuh jarak $35.1 \mathrm{~km}$

\section{Pelaksanaan Kegiatan}

Berikut ini adalah uraian mengenai pelaksanaan kegiatan berdasarkan susunan acara kegiatan yang telah dibuat, antara lain:

1. Sosialisasi Dilakukan dengan pemilik UKM untuk menyampaikan informasi-informasi mengenai latar belakang, target, sasaran dan tujuan kegiatan. Serta membahas mengenai jumlah peserta, peralatan dan tempat bimbingan pengembangan Desain Kemasan serta mekanisme pungganaan Desain Kemasan. Selain itu membahas mengenai konten dan konteks materi mengajar yang diinginkan disesuaikan kebutuhan.

2. Pengembangan dan Penerapan Penggunaan Desain Kemasan. Penerapan penggunaan Desain Kemasan tersebut dilakukan dengan interaksi dua sisi, dimana pada saat diskusi, peserta dapat langsung bertanya kepada instruktur. Penerapan Desain Kemasan ini berfokus pada dasar dan hal-hal pokok yang perlu diperhatikan dalam penggunaan Desain Kemasan, cara menggunakan Desain Kemasan dalam mempromosikan kerajinan pada UKM Heavenin. Adapun hasil pengembangan dan penerapan Desain Kemasan yang diberikan pada UKM untuk media promosi adalah:

a. Buka terlebih dahulu program Adobe Photoshop dan akan muncul tampilan seperti pada gambar 4 berikut ini. 


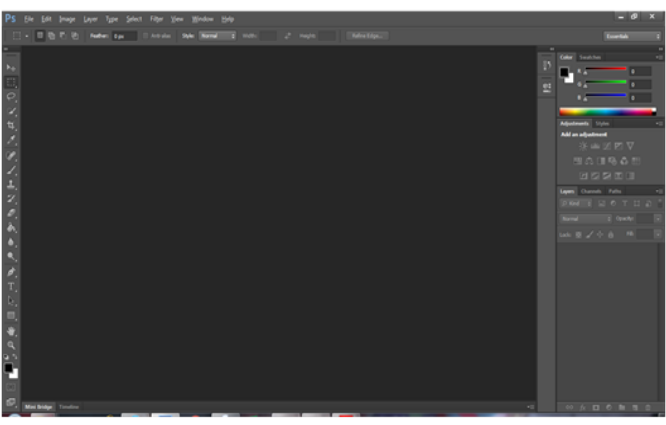

Gambar 4. Tampilan Awal Adobe Photoshop

b. Langkah berikutnya setelah membuka program Adobe Photoshop yaitu membuat ukuran dari label kemasan yang akan dibuat seperti terlihat pada gambar 5 beriku ini

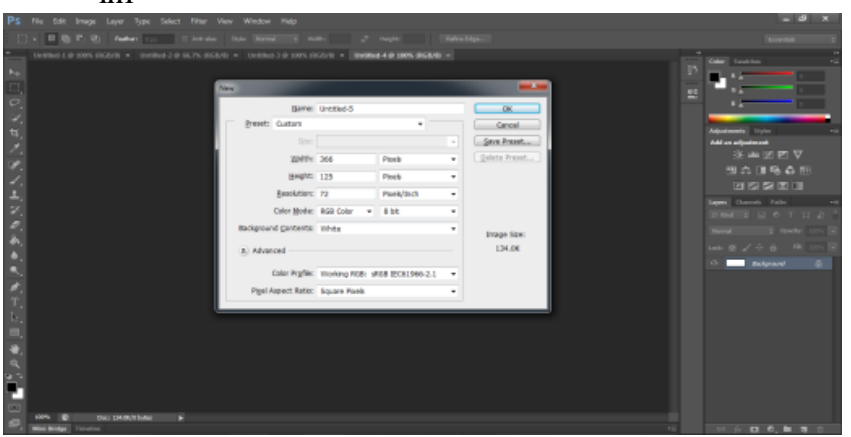

Gambar 5. Tamoilan Seting Ukuran

c. Langkah ketiga yaitu menulis label kemasan pada dokumen yang muncul setelah menentukan ukuran yang dikehendaki.

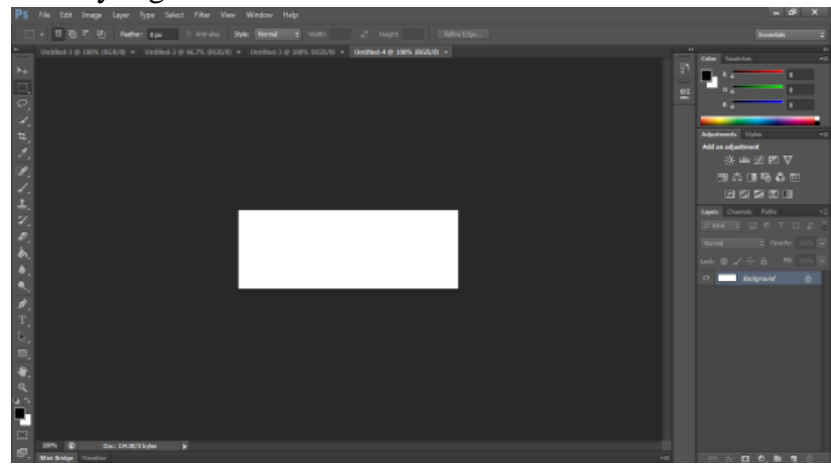

Gambar 6. Tampilan Setting Kertas Kerja

e. Langkah kelima merubah "AV" pada Tab character

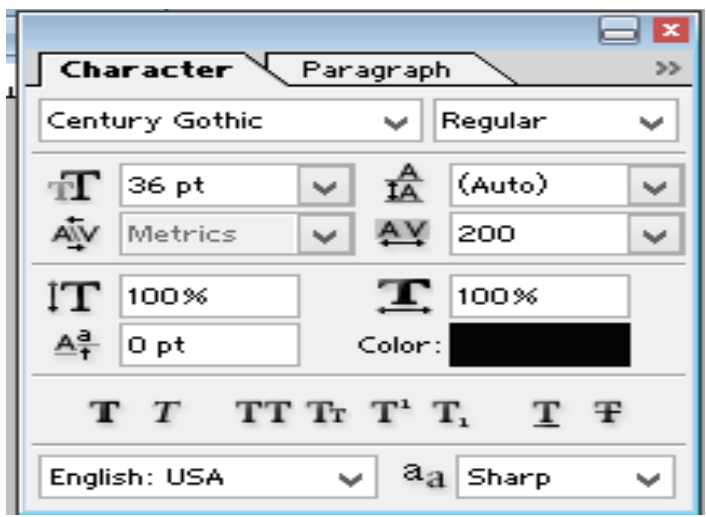

Gambar 7. Tampilan pengaturan character

f. Langkah keenam Pilih Binding Option -> centang Drop Shadow, option ->bevel and emboss

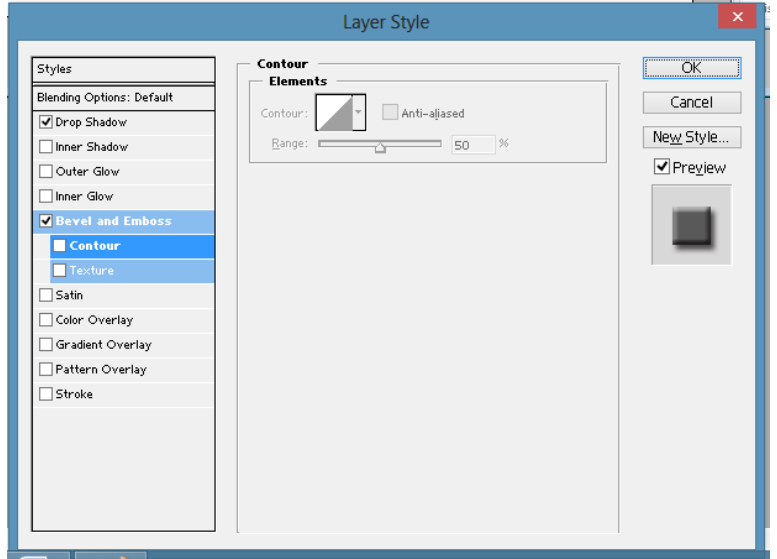

Gambar 8. Tampilan pengaturan efek pada text

g. Logo Dari UKM Heavenine

Berikut ini adalah logo dari UKM yang nantinya akan digunakan pada desain kemasan, dimana logo ini sudah dimiliki oleh UKM sebelum pelatihan desain ini dilaksanakan. Jadi pelatih tidak lagi membuatkan logo kusus utuk UKM.

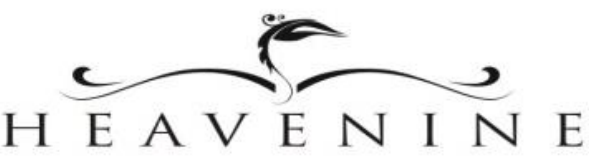

Gambar 9. Logo UKM Heavenie 
h. Setting Ukuran Paper Bag

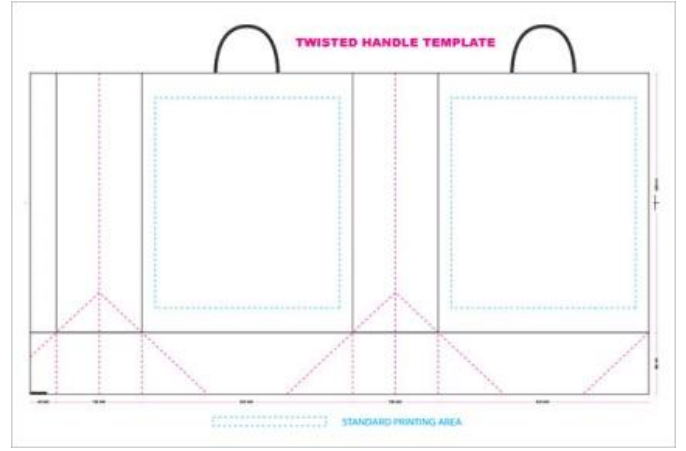

Gambar 10. Setting ukuran paperbag

i. Hasil Akhir Desain Kemasan

Berikutnya mulai mendesain model yang diinginkan pada paperbag, dimana berisikan logo UKM, alamat instagram dan nomor whatshaap dari pemilik UKM. Untuk lebih jelasnya dapat dilihat pada gambar 11

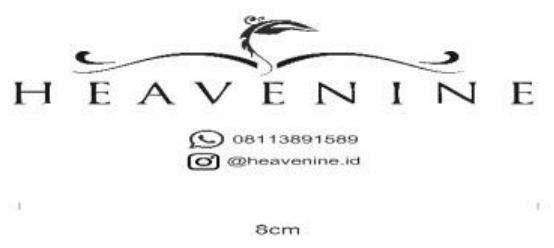

Gambar 11. Desain Kemasan

j. Hasil Akhir Desain kemasan

Langkah terakhir adalah menggabungkan antara logo yang sudah dimiliki dengan paper bag yang nantinya akan digunakan sebagai kemasa produk yang dijual. Dimana pada desain kemasan paperbag ini akan berisi informasi mengenai logo, alaman instagram yang sudah dimiliki UKM serta nomor whatshap dari pemilik UKM. Untuk lebih jelasnya dapat dilihat pada gambar 12 berikut ini.
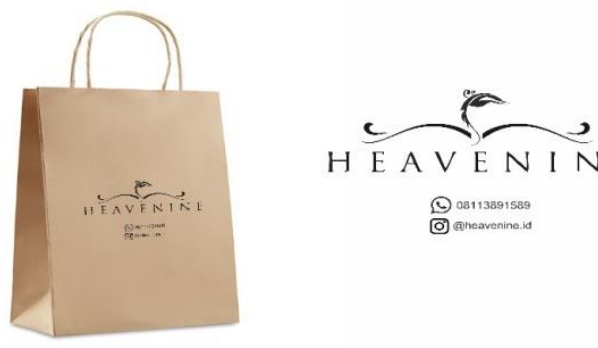

H E A V E I N E

(2) 08113891589

Gambar 12. Hasil Desain kemasan

3. Monitoring dan Evaluasi

Monitoring dan evaluasi dilakukan dengan melihat, menilai, serta memberikan masukkan berkaitan dengan hasil pengembangan penggunakan Desain Kemasan yang dihasilkan oleh peserta. Hasil presentasi tersebut sudah dibuat dengan sangat baik, terstruktur, serta fokus pada konteks dan konten yang diinginkan.

\section{KESIMPULAN}

1. Peserta pengabdian pada UKM Heavenine, memiliki antusia yang tinggi untuk mempelajari tentang bagaimana penggunaan Desain kemasan menggunakan paperbag, sebagai acuan dalam pemasaran.

2. Peserta memahami pentingnya memiliki ciri khas sendiri yaitu memiliki desain kemasan pada paper bag serta memahami pentingnya promosi dalam jaringan yang lebih luas.

\section{UCAPAN TERIMAKASIH}

Terima kasih kami ucapkan kepada Mitra Pengabdian dan kepada ITB STIKOM Bali yang memberikan pendanaan dalam mendukung terlaksananya kegiatan pengabdian dengan baik dan lancar.

\section{DAFTAR PUSTAKA}

[1] Anggraeni, R. M. (2018). Pemanfaatan Media Sosial Pada Pelatihan Go Online UMKM Se-Kecamatan Patuk, Gunungkidul Daerah Istimewa Yogyakarta.

[2] Amalia, A. (2018). Pelatihan Pemanfaatan Email Dan Google My Business Pada UMKM Kecamatan Patuk Kabupaten Gunungkidul Daerah Istimewa Yogyakarta. 
[3] Anwari, E., Meilani, E. \& Prasety owati, O., 2018. Perancangan Grafis Kemasan Makanan Burayot Sebagai Oleh-Oleh Khas Garut. DeKaVe, 10(2), pp.12-24.

[4] Cahyadi, A.B., Sugiono \& Efranto, R.Y., 2014. Perumusan Strategi Unggulan Jasa Bus DAMRI Berbasis Analais SWOT dan Quality Function Deployment ( QFD ). Jurnal Rekayasa dan Manajemen Sistem Industri, 2(1), pp.80-91.

[5] Hartanto, S., 2015. Perancangan Desain Kemasan Produk Homemade Pie "391" Surabaya. Jurnal DKV Adiwarna, 1(6).

[6] Januhari,Ni Nyoman Utami, Purwantara, I Made Adi,2018. "Pelatihan Penggunaan Internet Sebagai Media Pemasaran Online Pada KWT VCO Tabanan" WIDYABHAKTI JURNAL ILMIAH POPULER V.1(1): November. 